Session 2793

\title{
Getting to know your engineering major
}

\author{
Christopher J. Rowe, Anita Mahadevan-Jansen \\ Vanderbilt University
}

\begin{abstract}
The first semester in engineering education is arguably the most important in laying the fundamental groundwork and preparing students for advanced study in their choice of engineering major. An estimated $40 \%$ of entering freshmen are uncertain as to their choice of major. Students are typically required to declare their engineering major as freshmen. The burden and the goal of this project then is to educate students about engineering and about their specific major so that they can make an informed decision. Thus, a new freshman program is being established to address these concerns both in and out of the classroom. These efforts are being implemented in conjunction with the redesign of the introductory engineering course (ES 130) offered at Vanderbilt University from a skills-based approach to a problem-solving approach.

An integral part of the introductory engineering course is a semester long project. In order to (a) familiarize the freshman with the different engineering majors and (b) incorporate the engineering design process into the curriculum, discipline-specific engineering design projects have been implemented into the freshman Engineering course. The discipline-specific projects allow students to work in small teams of 3-5 on an engineering problem in their selected major. Each of the projects is sponsored by a faculty member who has volunteered to serve as a guide for the project; this additionally facilitates one-on-one student-faculty interaction. This new paradigm is compared to the discipline-aspecific projects implemented in the freshman course this far and analyzed in conjunction with student feedback on confidence in choice of major and engineering design-based problem-solving skill.

To further bring the various engineering majors to life for the freshmen outside the classroom, a series of weekly panel discussions were held for each degree program in the School of Engineering at Vanderbilt University. Each panel consisted of an engineering alumni practicing in the chosen field, a faculty member, a graduate student and an undergraduate student. Preliminary results indicate a heightened interest in these panels and positive response to these activities by all students, not just freshmen.
\end{abstract}

\section{The Problem}

Studying engineering is unique in that it is a true 4-year professional degree. Most engineering programs tend to be well structured especially in the first two years, forcing the declaration of a major discipline within engineering fairly early in the curriculum. A primary problem with this requirement is that students are asked to make this decision before they have

Proceedings of the 2003 American Society for Engineering Education Annual Conference \& Exposition Copyright $\left({ }_{0}\right.$ 2003, American Society for Engineering Education 
had an opportunity to learn much about engineering or their major discipline. Amidst pressures of eliminating the concept of a common freshman year to expand departmental course offerings, this problem is particularly magnified as surveys conducted in previous years indicate that nearly half of the entering engineering students are unsure of their choice of major.

At Vanderbilt University School of Engineering (VUSE), the first year is a mostly common freshman curriculum that provides for the option of changing majors anytime in that year without penalty to the student. It has been found, however, that most students who enter engineering, and declare a major upon applying, have only a vague idea of what their intended major is about, and do not fully understand their options as first-year engineering students. With misinformation or lack of information comes dissatisfaction with the chosen program, substandard performance in the program and change of major late in the curriculum resulting in delayed graduation. Thus there is much debate on how to strike a balance between the need to include discipline specific courses early in the engineering program while giving students an opportunity to make an informed decision.

\section{Introduction to Engineering}

Engineering Science 130 is the introductory course in engineering required of all first-year students at VUSE. This course has typically been taught as a computing proficiency course to equalize the skills of the entering freshmen in preparation for subsequent, discipline-specific courses. Traditionally this course has been taught in a generic manner with little emphasis on discipline specific topics or examples and course content was centered around team building, HTML, Excel and Matlab. While the course fulfilled the need of the entering students in the past, the past 2-3 years has shown increasing proficiency in computing by the students pointing to a need to modify the curriculum to meet the demand of today and tomorrow's students.

Incidentally, this is also the course that introduces students to Engineering, and, therefore, ideas have developed in the last two years on enhancing the freshman engineering experience in the context of this course as well as outside the classroom. The ideas described in this paper which include discipline-specific projects and major panel discussions, were implemented in parallel to other developments in the context of this course (discussed in a paper in session 1653). The goal of this paper then is to educate the students on (a) Engineering and Engineering design and (b) the various Engineering majors both directed towards aiding them in their selection of a major.

\section{Semester Design Project}

The traditional format for the semester design project in ES 130 requires students in each section of the course to form a team and choose a topic. Since the selection of the topic occurs within the first 6 weeks of the course, these topics are typically web-based projects focusing on online information websites, 3-D animation and graphic scenes, online games and a few ecommerce sites. This is primarily because when the project selection is due, only a third of the syllabus has been completed much of which is focussed on the Internet, HTML and VRML. Thus the choice of topics are colored by the student knowledge up till that point in time. While such

Proceedings of the 2003 American Society for Engineering Education Annual Conference \& Exposition Copyright $\left({ }_{0}\right.$ 2003, American Society for Engineering Education 
projects are still useful in educating students on team building, project development and management, the level of technical detail is minimal.

In order to increase the level of engineering and introduce discipline-specific as well as multidisciplinary aspects to the projects, a new format has been developed. This alternate project format is intended to expose students to engineering and their potential major, give them a sense of the Engineering Design process, and develop their teamwork skills. Student groups are expected to follow the engineering design process in working on their project. Each project group consists of 3-5 people grouped by their chosen major. Each group selects their own project from a project list in their group major compiled by the authors of this paper. In order to present checkpoints over the course of the project, to discourage last minute scramble and to simplify grading, students were required to submit a proposal, two progress reports, a final paper and final presentation at specific due dates which allows the instructor to stay informed on their progress.

The students choose their semester project based on the interests of all members of the group within the group major. Each project has a real world application and is presented in a commercially viable format such as a contractual bid, consulting project, etc. In proposing and completing the projects, each group has to consider several aspects of the project including the:

- Technical

- Financial

- Legal

- Marketing

- Safety/Liability

- Ethical Issues

Each of these six aspects of the projects has to be discussed in their proposal, progress reports, final presentation, and final report.

\section{Design Project Implementation}

The initial idea of developing major-specific design projects volunteered by faculty members involved in active research along with direct faculty guidance was formulated and implemented on a small scale in Fall 2001. The list of discipline projects was compiled by direct contact with faculty members with active research as well as pedagogical interests. Faculty who agreed to participate offered a project idea based on their current research interests. These topics varied as a part of an existing project, a recently completed project, an external contractual project, or a major focus of their ongoing research. Since faculty involvement in this pilot idea was completely voluntary, faculty contact with the groups was kept at a minimum so as to not overload the participating faculty. Thus most faculty met with their group(s) between $3-5$ times over the course of the semester; 1) an initial meeting to familiarize the group with the project and provide relevant reading material, design specifications as well as project endpoints, 2) a mid-project meeting to make sure the group was on the right track, and 3) another meeting towards the final due date to obtain approval of their final design. 
In Fall 2001, 3 of 10 sections of the course totaling 93 students adopted the alternate project format. The original project list contained 20 topics grouped by major (Biomedical, Chemical, Civil, Electrical \& Computer, Environmental and Mechanical Engineering) with 6 projects crosslisted in two departments for groups that had more than one discipline or interest represented. Conceivably, a faculty member could have a maximum of 3 groups to guide, one from each section, as groups within a course section were required to choose a unique project. In the first implementation, the potential for overload was not a problem, although indications of future problems, if implemented on a wider scale, were highlighted. The semester projects culminated in a Project Fair held at the end of the fall semester where projects are displayed for the entire engineering student body, faculty and administration. Specific surveys were conducted amongst the participating students as well as faculty guides. In general, the new design format of the projects was well received by students, faculty and administration. The concept of including a faculty guide and using current research based topics helped foster student-faculty interaction and gave students a point of contact (a familiar face) in the major department in addition to their academic advisor. A majority of the faculty guides indicated that the time commitment allotted to this effort was minimal and did not disrupt their normal academic activities and they agreed to participate in the future. Based on the quality of work presented and the overall success of this project format, as evidenced by faculty as well as students, a commitment was made to expand the format to encompass more ES130 sections in the next academic year.

In Fall 2002, 5 of 10 sections utilized the alternate project format. This gradual ramp-up from three sections to five sections was necessary in order to gauge the number of projects necessary in the master list, which in turn determined the number of faculty guides needed to volunteer in its implementation. The more the projects offered, the fewer student groups there are per faculty guide. We found that a faculty member can guide a maximum of three groups doing the same project while maintaining his or her normal work schedule; although one or two groups is ideal. Since the level of involvement on the faculty's part is minimal, faculty willingness was not a problem at this point. Of course, some direct solicitation was necessary to achieve the desired number of projects.

In this implementation (fall 2002), the project list contained 26 topics grouped by major with 12 projects cross-listed in two disciplines. The number of students participating rose from 93 to 166. A table illustrating the project format expansion is shown below:

\begin{tabular}{|llll|}
\hline Semester & Fall 2001 & Fall 2002 \\
\cline { 2 - 4 } & Total Projects & 20 & 26 \\
\cline { 2 - 4 } & Total Projects Cross-listed & 6 & 12 \\
\cline { 2 - 4 } Course Sections Participating & 3 of 10 & 5 of 10 \\
\cline { 2 - 4 } & Number of groups per faculty & 2 & 2 \\
\hline Total Students Participating & 93 & 166 \\
\hline
\end{tabular}

Figure 1: Project format expansion from Fall 2001 to 2002.

This alternate project format has been well received across both students and faculty in both implementations of the format. Targeted responses indicate that the primary goals in incorporating this project format, namely, increased technical content in the projects, heightened awareness

Proceedings of the 2003 American Society for Engineering Education Annual Conference \& Exposition Copyright (C) 2003, American Society for Engineering Education 
about engineering as well as specific engineering major as well as direct contact with major faculty, were successfully achieved. In future semesters, we plan to continue to grow this project format to include all introductory course sessions by continuing to add projects and faculty guides.

\section{Major Panel Series}

The idea of creating a series of discipline-specific panel discussions arose from direct interaction with many of our first year engineering students who indicated their lack of preparedness and information in choosing their engineering major. Students are required to make this commitment by the end of their freshman year at VUSE. Even though only $3 \%$ of the entering freshman class last year had not committed to a major, nearly half of the class was unsure of their decision. Thus, in an effort to strengthen our first-year curriculum and service to our freshman in Engineering, a series of 10 panel discussions, one for each engineering major offered at VUSE were initiated. The main purpose of the series was to expose freshman to the various fields of engineering from different perspectives and better assist them in making an early, but informed, decision on their major course of study. Participating in each panel was a practicing engineer, a faculty member, a graduate student and a senior undergraduate student. During each panel, each panelist was asked to present a short summary of their choice of major followed by a question and answer session. The following table provides the schedule used for the panel series as implemented in Fall 2002.

\begin{tabular}{|ll|}
\hline Date & Major \\
\hline August 29, 2002 & First week of class \\
\hline September 5, 2002 & open \\
\hline September 12, 2002 & Biomedical Engineering \\
\hline September 19, 2002 & Civil Engineering \\
\hline September 26, 2002 & Engineering Science \\
\hline October 3, 2002 & Environmental Engineering \\
\hline October 10, 2002 & open \\
\hline October 17, 2002 & Electrical Engineering \\
\hline October 24, 2002 & Computer Engineering \\
\hline October 31, 2002 & Computer Science \\
\hline November 7, 2002 & Biomedical Engineering \\
\hline November 14, 2002 & Chemical Engineering \\
\hline November 21, 2002 & Mechanical Engineering \\
\hline November 28, 2002 & Thanksgiving Break \\
\hline December 5, 2002 & open \\
\hline December 12, 2002 & Last week of class \\
\hline
\end{tabular}

Figure 1. Panel discussion schedule

Proceedings of the 2003 American Society for Engineering Education Annual Conference \& Exposition Copyright (C) 2003, American Society for Engineering Education 
As shown in the table, a different major was featured each week with similar majors (i.e. EE, $\mathrm{CmpE}, \mathrm{CS}$ ) grouped together to provide some consistency in topic. In inviting the practicing engineers, we chose to first target local alumni who had previously expressed interest in being involved with the undergraduate population. On the rare occasion a local alumnus was not available, alternate contacts were sought.

\section{Major Panel Series Implementation}

Each panel major was chosen according to department offerings at VUSE, with multiple panels scheduled in the case of the Electrical Engineering \& Computer Science department and the Civil \& Environmental Engineering department. The decision was made to separate the components within these majors in order to keep the discussion topics as focused as possible. The Engineering Science program is our interdisciplinary engineering program, which contains tracks in all the engineering departments and Management of Technology. Engineering Science and Computer Science are our only non-accredited engineering programs (B.S. vs. B.E.), but are included in the list of engineering majors and thus the panel majors.

The student-run Engineering Council volunteered to organize a reception for the participants and attendees following each panel discussion. The Engineering Council has sponsored lunchtime information sessions on the various majors in the past, which have suffered from poor attendance and thus were glad for this opportunity. The panels were scheduled at a regular time maintained throughout the series, considered to be the most convenient time possible for most participants based on Various student organization meetings, classes, labs and evening exams in lecture courses such as chemistry. Issues such as student work schedules, ROTC activities, and other volunteer activities were impossible to anticipate. Individual cases of schedule conflicts were handled on a case-by-case basis.

The entire series was managed using Vanderbilt's course management software - Prometheus. This vehicle facilitated maintaining record of student attendance, and provided an avenue for electronic surveys. Prometheus was also used for information exchange relevant to the panels such as summaries of the participating panelists. A list of sample questions specific to a given major was also posted prior to each panel to ensure initiation of student-panelist discussion during the Q\&A session.

While the primary audience for these panel discussions was the freshman engineers, the panels were also opened to all upperclassmen and faculty. Department chairs were particularly encouraged to attend relevant panels. It was observed that those sessions that included multiple department faculty members generated the most questions and discussion. Since this program was directed towards the freshman, and electronic attendance-taking was possible, the option of making attendance to one or more of these panels mandatory was left to the discretion of the ES 130 instructors. Four sections mandated attendance to a minimum of 2 panels, as a requirement for the course. In addition to attendance, a brief survey was given at the end of each session. The results from the survey were collected anonymously and analyzed. 
In general, the panels were well attended from a minimum of 22 attendees to a maximum of 96 attendees. While some of this attendance could be attributed to mandatory attendance, it could not account for all of these numbers, as survey results indicated attendance from all 10 sections of ES 130 at each of the 10 panels. Most attendees indicated that they would recommend the panels to other students. The main criticism received was that there was insufficient time for discussion in some panels.

\section{Conclusions}

\section{Design Project}

Feedback from students shows that they have a better understanding of what their indicated major involves, are more proficient in the design problem solving process and have benefited from contact with faculty in their department. The following table illustrates the benefit realized by students in both formats:

\begin{tabular}{|lc|}
\hline $\begin{array}{l}\text { Has the semester project helped you in making } a \\
\text { decision on your major? }\end{array}$ \\
\hline $\begin{array}{l}\text { Computer-based project format } \\
\text { Discipline-specific design project format }\end{array}$ \\
\hline
\end{tabular}

Figure 3. Student feedback on aiding in major decision-making

Based on the end-of-semester survey results, $39 \%$ of the students involved in the alternate design project format said that the project helped them in their decision on a major. Of the students who participated in the computer-based format, only 3\% stated their project experience helped them decide on a major. Ninety-one percent of the entire freshman class completed the end-ofsemester survey.

\section{Major Panel Series}

Overall the major panel series was a great success. Overwhelmingly, the respondents stated that the sessions were extremely helpful and would recommend them to classmates and friends. Several students recommended that more practicing engineers should sit on the panels to give a picture of the various types of careers available. While this is good feedback, a smaller number of panelists allows for more discussion time.

Based on information provided in the end-of-semester surveys, students were asked to check which of nine items helped them decide or learn more about their major. Figure 4 illustrates the distribution. Thirty-seven percent of the respondents stated that the engineering major panels helped them settle on a decision about their major. This is the largest percentage of the nine options, which is encouraging feedback. It is known that at least four of the ten instructors gave participation credit for attendance to at least two panels; which promoted attendance. The second most influencing factor according to the student respondents was the introductory course itself, and the next highest percentage was the instructor, which is not entirely surprising. 


\begin{tabular}{|c|c|}
\hline \multicolumn{2}{|c|}{$\begin{array}{l}\text { Which of the following have helped you in your } \\
\text { decision on a major? }\end{array}$} \\
\hline ES 130 - the course & $32.6 \%$ \\
\hline Engineering Panel Series & $37.0 \%$ \\
\hline Semester Project & $21.6 \%$ \\
\hline Faculty Instructor & $28.2 \%$ \\
\hline Upperclassmen & $21.9 \%$ \\
\hline Professional Societies & $7.2 \%$ \\
\hline Academic Advisor & $14.7 \%$ \\
\hline Other & $20.7 \%$ \\
\hline None of the Above & $15.0 \%$ \\
\hline
\end{tabular}

Figure 4. Influencing factors in decision on a major

Ultimately, the enhancements made to the first-year program were successful. The most encouraging aspect of the improvement is the ease of implementation. The cost of the design projects is essentially zero, not including the small amount of time the faculty guides spent with students. The cost of the major panel series only includes the cost of the receptions, which had already been allotted to the Engineering Council from the Dean's Office. All panel members volunteered to participate. Based on this feedback, these programs will be continued in the future, and will hopefully be worked into any future improvement or redesign of the freshman curriculum.

\section{Biographical Information}

CHRISTOPHER J. ROWE received his Bachelor of Engineering degree in Biomedical Engineering and Master of Engineering degree in Management of Technology from Vanderbilt University in 1996 and 1998, respectively. He joined the Electrical Engineering and Computer Science faculty in January 2003. His research interests include technical program and project management and serves as freshman year coordinator for the Engineering Dean's Office.

Anita Mahadevan-Jansen received her Master's and Doctoral degrees in Biomedical Engineering from the University of Texas at Austin 1993 and 1996 respectively and has been a faculty member in the Department of Biomedical Engineering at Vanderbilt University since 1998. Her expertise is in optical spectroscopy and imaging for the detection of tissue physiology and pathologies. She is a domain expert in the NSF-funded VaNTH-ERC for Bioengineering Education and is actively involved in the development of the freshman curriculum. 